\title{
Development and Validation by Reverse Phase High Performance Liquid Chromatography Method for the Estimation of Piperine and Coenzyme Q10 in Bulk and Pharmaceutical Dosage Form
}

\author{
M. SARKAR, PUJA BAG, B. KUMAR AND POOJAA.CHAWLA* \\ Department of Pharmaceutical Analysis, ISF College of Pharmacy, Moga, Punjab 142001, India
}

Sarkar et al.: Reverse Phase High Performance Liquid Chromatography Method for Estimation of Piperine and Coenzyme Q10

\begin{abstract}
Today people are focused on their health, as good health is a key to the happiness of our life. Medicine takes a big responsibility to take care of our health. Various supplements are available to meet the nutritional requirement. One such supplement is a combination of piperine and coenzyme Q10. The medicines have to be analyzed properly before introducing them to the market. As no analytical method is available for simultaneous estimation of the combination, hence an attempt was made to develop a validated method for the estimation of piperine and coenzyme Q10 simultaneously in bulk and its dosage form. A simple, precise, accurate and validated reversed phase high performance liquid chromatography technique was developed for the estimation of piperine and coenzyme Q10 in bulk and its tablet formulation. In this developed method, Waters $X$ Bridge $C_{18}$ column $(250 \mathrm{~mm} \times 4.6 \mathrm{~mm}, 5 \mu \mathrm{m})$ was used as a stationary phase and acetonitrile, tetrahydrofuran and water was used in 65:32:3 (v/v) ratio as mobile phase with $1 \mathrm{ml} / \mathrm{min}$ flow rate. This isocratic separation was accomplished using Waters 2707 Autosampler high performance liquid chromatography system, Waters 515 solvent delivery system, with photodiode array detector detection at $275 \mathrm{~nm}$. Chromatographic data was processed by Empower 2 software. The retention times of coenzyme Q10 and piperine were 4.56 and $8.19 \mathrm{~min}$ respectively. The linearity ranges have lied between 4-6 $\mu \mathrm{g} / \mathrm{ml}, 240-360 \mu \mathrm{g} / \mathrm{ml}$ for piperine and coenzyme Q10 respectively with 0.997 as correlation coefficient for both.
\end{abstract}

Key words: Piperine, coenzyme Q10, reversed phase high performance liquid chromatography, method validation, limit of detection, limit of quantitation

Coenzyme Q10 (CoQ10) is a vitamin like nutraceutical which was found out by Frederick Crane and his colleagues at the University of Wisconsin in $1957^{[1]}$. Chemically, it is a 2,3 dimethoxy-5 methyl-6 decaprenyl benzoquinone, having 10 isoprene units associated in the side chain and also known as ubiquinone or ubidecarenone $^{[2]}$ (fig. 1). It is chemically produced in the body and found in fish, meat, nut and various oils $^{[3]}$. CoQ10 is very popular for its potent antioxidant property, has a vital role in Adenosine Triphosphate (ATP) productions through the electron transport chain in mitochondria, cardioprotective, nephroprotective and membrane stabilizer ${ }^{[4]}$. CoQ10 is a higher molecular weight $(863.34 \mathrm{~g} / \mathrm{mol})$ highly lipophilic compounds which come under Biopharmaceutical Classification System (BCS) class $\mathrm{II}^{[5]}$ (fig. 1), practically insoluble

*Address for correspondence

E-mail: pvchawla@gmail.com

November-December 2021 in water ${ }^{[6]}$, dietary absorption of Q10 is very mild and confined $^{[7]}$. CoQ10 has an outstanding safety profile, as proved by a large number of preclinical and clinical studies, in both adults and children ${ }^{[8-10]}$. For adults and pediatrics doses were up to $1200 \mathrm{mg} / \mathrm{kg} / \mathrm{d}$ and $8 \mathrm{mg} /$ $\mathrm{kg} / \mathrm{d}$ respectively. Several clinical trials have identified the use of CoQ10 as adjuvant care in cardiovascular, neurodegenerative disorders and myopathies of the mitochondria ${ }^{[11-13]}$. According to the National Cancer This is an open access article distributed under the terms of the Creative
Commons Attribution-NonCommercial-ShareAlike 3.0 License, which
allows others to remix, tweak, and build upon the work non-commercially,
as long as the author is credited and the new creations are licensed under
the identical terms

Accepted 01 November 2021

Revised 06 April 2021

Received 29 November 2020

Indian J Pharm Sci 2021;83(6):1208-1214 


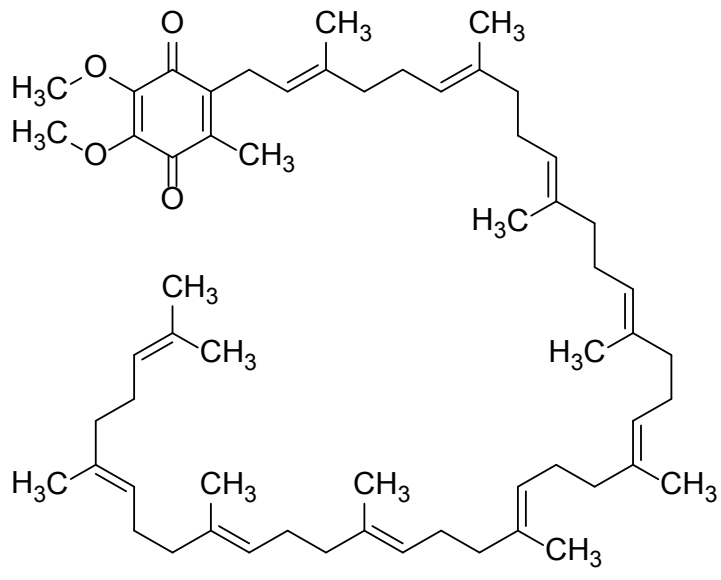

Fig. 1: Structure of CoQ10

Institute (NCI) people having low CoQ10 levels in the blood, were associated with myeloma, lymphoma and cancers of breast, lung, prostate, pancreatic, colon, kidney, head and neck. However, the researchers proposed that $\mathrm{CoQ} 10$ stimulates the immune system and can also be beneficial in secondary cancer treatment.

Piperine is part of a group of compounds known as "Vanilloids," because they are identified by the existence of a functional group depend on the structure of vanillin. Piperine is a natural substance present as the principal pungent component (1-9\%) in several portions of a plant which belong to the Piperaceae family ${ }^{[14]}$. Piperine, the most enormous alkaloid in pepper, was first identified by Hans Christian Ørsted from the pepper extract in 1819. It was collected as a crystalline yellow compound with a melting point between 128 and $130^{\circ}$. Piperine's chemical structure was later known as piperoylpiperidine, with the chemical formula $\mathrm{C}_{17} \mathrm{H}_{19} \mathrm{NO}_{3}$ and with the International Union of Pure and Applied Chemistry (IUPAC) name 1-(5-[1,3-benzodioxol-5-yl]-1-oxo-2,4-pentadienyl) piperidine (fig. 2). Piperine was reported to be a weak base that breaks down to volatile basic piperine, known as piperidine $\left(\mathrm{C}_{5} \mathrm{H}_{11} \mathrm{~N}\right)$ and piperic acid $\left(\mathrm{C}_{12} \mathrm{H}_{10} \mathrm{O}_{4}\right)$ after acid or alkali hydrolysis ${ }^{[15]}$. Piperine is highly soluble in alcohol, ether and chloroform and slightly soluble in water ${ }^{[16]}$. Various studies proved that piperine has versatile beneficial activities such as immunomodulatory, anticarcinogenic, stimulatory, hepatoprotective, anti-inflammatory, antimicrobial and antiulcer activities ${ }^{[17-19]}$. It was also used for improving the circulation of blood, enhancement of the flow of saliva and provoking appetite ${ }^{[20]}$. Another main function of piperine is to enhance the bioavailability of various drugs, vitamins and nutraceuticals by increasing the absorption or decelerating the metabolism of the drugs $\mathrm{s}^{[21-23]}$. Literature reveals that several methods such as Ultraviolet (UV), High Performance Liquid Chromatography (HPLC) are used for estimation of piperine and also HPLC methods are reported for CoQ10 but no single HPLC method is reported for simultaneous estimation of CoQ10 and piperine. Therefore, this study can describe a simple, rapid, precise, economical and accurate Reverse Phase High Performance Liquid Chromatography (RP-HPLC) method for the development and validation of CoQ10 and piperine in the combined pharmaceutical dosage form. Here Qubinor tablet (CoQ10/ubedicarenone and piperine) is used as a nutritional supplement that contains a high absorption form of CoQ10 available, ubidecarenone. CoQ10 helps the body's cells in energy production and has antioxidant properties that protect the body's cells from damage caused by oxidative stress and free radicals.

In the sight of useful pharmacological effects of CoQ10, the feasible role of piperine is for the enhancement of bioavailability.

\section{MATERIALS AND METHODS}

\section{Chemical reagents:}

Piperine was obtained as generous gift sample from Unico Pharmaceuticals, Ludhiana India and CoQ10 from La-Pharma Ludhiana, India. Acetonitrile (ACN), methanol and Tetrahydrofuran (THF) (HPLC grade) was purchased from Rankem (New Delhi, India), HPLC grade water was collected from water purification systems Elix 03 (Millipore, USA) in our institutional water plant. $0.45 \mu \mathrm{m}$ Millipore membrane filter and syringe filter were purchased from local market. The pharmaceutical dosage forms used in the study was Qubinor tablet containing $300 \mathrm{mg}$ of CoQ10 and $5 \mathrm{mg}$ of piperine. Tablets were purchased from online pharmacy named $1 \mathrm{mg}$.

\section{Instrumentation:}

The analysis was carried out on Waters (2707) autosampler HPLC system, Waters 515 solvent delivery system, with Photodiode Array (PDA) detector. Empower-2 software was used for chromatographic

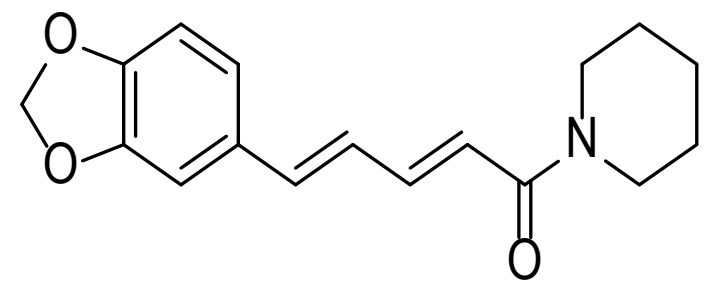

Fig. 2: Structure of piperine 
data processing. PCI analytics ultrabath sonicator was used for mixing and sonication purpose. Agilent Cary 630 Fourier-Transform Infrared (FTIR) spectrometer with Microlab software and Shimadzu-1700 UVSpectrophotometer with UV probe software had used for Active Pharmaceutical Ingredients (APIs) confirmation, Analytical Balance Mettler Toledo, AB204-S/FACT had used for weighing purpose.

\section{Chromatographic conditions:}

The mobile phase consisted of ACN, THF and HPLC water $(65: 32: 3)$ was used in isocratic mode through Waters $X$ Bridge $C_{18}$ column $(250 \mathrm{~mm} \times 4.6 \mathrm{~mm}$, $5 \mu \mathrm{m}$ ) with flow rate of $1.0 \mathrm{ml} / \mathrm{min}$ and run time $20 \mathrm{~min}$. Detection was done at $275 \mathrm{~nm}$ wavelength. Column temperature was set at $40^{\circ}$. Mobile phase was filtered through $0.45 \mu \mathrm{m}$ Millipore filter paper and degassing by sonication before running into the system.

\section{Preparation of standard solutions:}

Standard stock solutions of CoQ10 and piperine were prepared as $1000 \mathrm{ppm}$ concentration by taking $10 \mathrm{mg}$ of both in $10 \mathrm{ml}$ volumetric flask individually. Mobile phase was used as a diluent, before the final make up solution had sonicated. From this 1000 ppm, both standard and stock, $300 \mathrm{ppm}$ and 5 ppm (as per label claim) target concentration was prepared for CoQ10 and piperine respectively. Then for further validation study, mixed the two target concentrations as equal amount and continued the study as per International Council for Harmonisation (ICH) Q2(R1). The CoQ10 solution was kept in amber coloured volumetric flask due to its light sensitivity.

\section{Preparation of sample solution:}

20 tablets were crushed and as per label claim calculated $10 \mathrm{mg}$ equivalent weight was taken in a $10 \mathrm{ml}$ volumetric flask to make upto $1000 \mathrm{ppm}$ as test stock and then prepared the test concentrations of $300 \mathrm{ppm}$ and $5 \mathrm{ppm}$ for the estimation of CoQ10 and piperine, respectively. Mobile phase was used as a diluent. All the test solutions were kept in amber colored volumetric flask.

\section{RESULTS AND DISCUSSION}

Various trials were used by changing the composition of the mobile phase to develop a sensitive HPLC method to estimate piperine and CoQ10 simultaneously. The developed method was appropriate with good linearity, precision and accuracy.

According to the United States Pharmacopeia (USP) guideline, the system suitability test was fulfilled by studying few parameters like theoretical plate, retention time, peak area, capacity factor, asymmetry factor, etc. Five duplicates of standard stock solution of drug piperine and CoQ10 were taken and analysis was performed at the optimized chromatographic conditions. The results are discussed in Table 1.

The developed RP-HPLC method was validated according to ICH guideline parameters ${ }^{[24-26]}$.

Specificity may be explained as the power of an analytical method to accurately distinguish the analyte in the presence of another potential sample mixture. The specificity is assessed by injecting the blank and sample solution. The entire identification followed by the separation of piperine and CoQ10 by the RP-HPLC technique was obtained with no interference (fig. 3) which corroborates the specificity of the developed method.

The linearity of the HPLC method was performed by preparing six concentrations of piperine and CoQ10 standard solution in methanol from their stock solution individually. The linearity was followed in the concentration range of $4-6 \mu \mathrm{g} / \mathrm{ml}$ for piperine and $240-360 \mu \mathrm{g} / \mathrm{ml}$ for CoQ10 with 0.997 as correlation coefficient for all (fig. 4-fig. 6). The results confirmed that the concentration range in which the standard curve of linearity was performed has good reproducibility as per Table 2.

The value of Limit of Detection (LOD) was found to $0.21 \mu \mathrm{g} / \mathrm{ml}$ and $2.79 \mu \mathrm{g} / \mathrm{ml}$ for piperine and CoQ10

\section{TABLE 1: SYSTEM SUITABILITY PARAMETERS}

\begin{tabular}{lcccc}
\hline Sr. No. & Parameters & USP limit & CoQ10 & Piperine \\
\hline 1 & Concentration (\%) & - & $100 \%$ & 100 \\
2 & Retention time (min) & - & 4.56 & 8.19 \\
3 & Average peak area & - & 42410.5 & 622697.3 \\
4 & \% RSD of peak area & $\leq 2.0$ & 0.904 & 0.773 \\
5 & Peak asymmetry & $\leq 1.5$ & 0.786 & 0.647 \\
6 & Mean no. of theoretical Plate & $\geq 2000$ & 3500 & 5500 \\
7 & Final retention time (min) & - & 4.606 & 8.280 \\
\hline
\end{tabular}




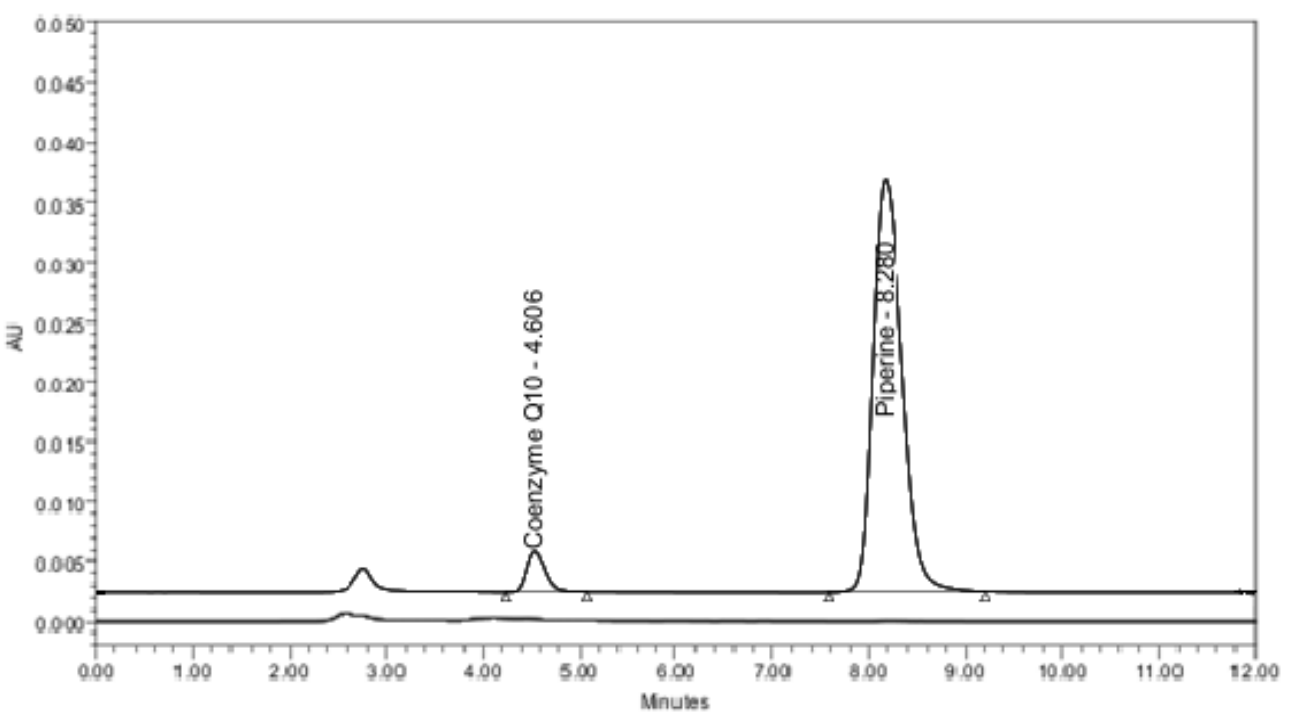

Fig. 3: Overlay of blank chromatogram with sample showing no interferences

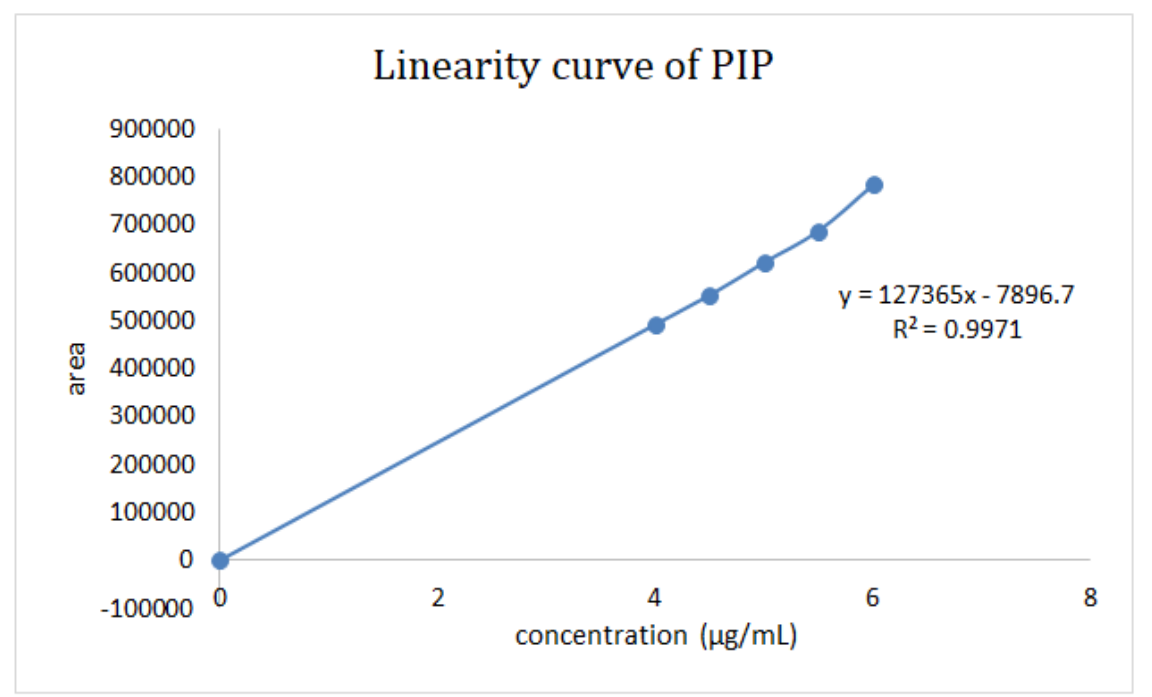

Fig. 4: Linearity curve of piperine

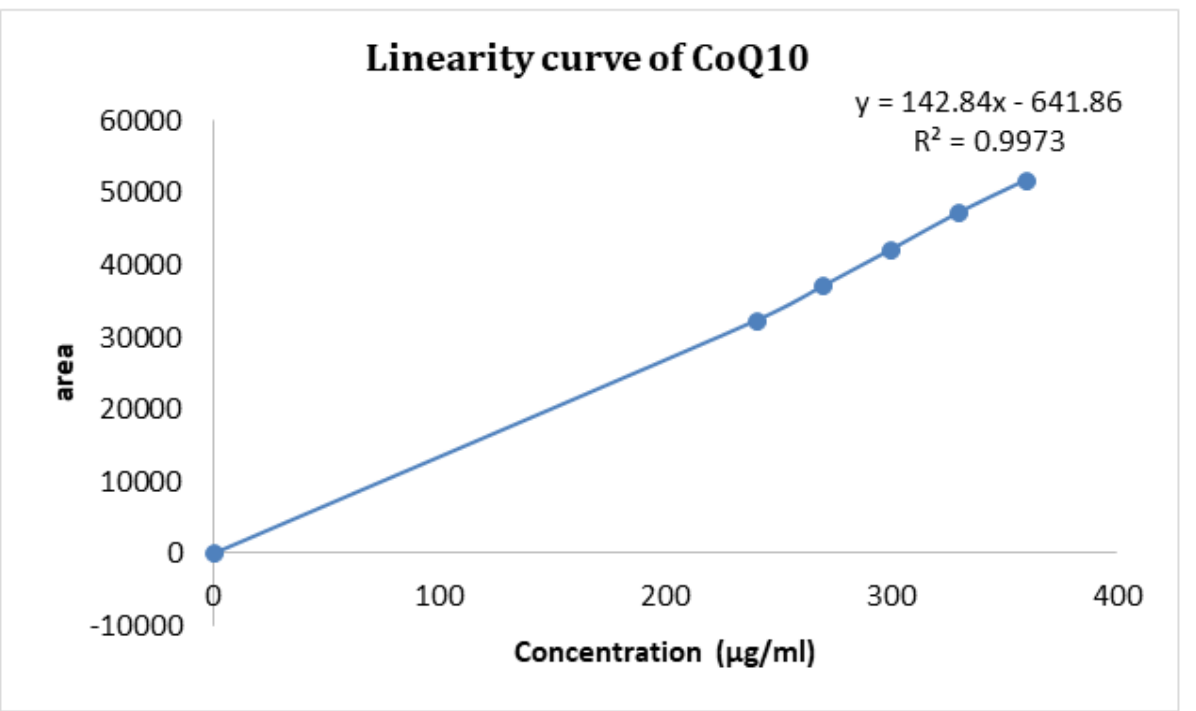

Fig. 5: Linearity curve of CoQ10 


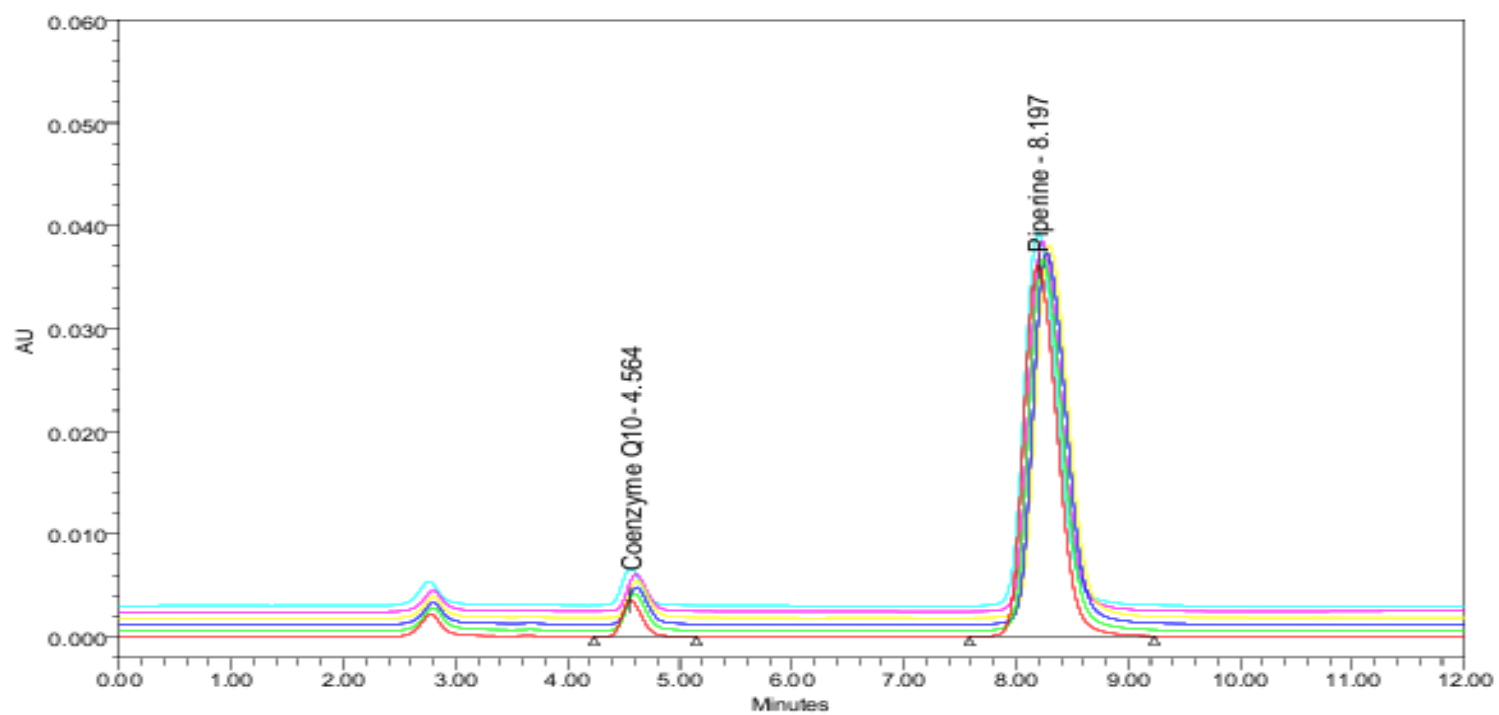

Fig. 6: Overlay chromatogram of CoQ10 $(240-360 \mu \mathrm{g} / \mathrm{ml})$ and piperine $(4.0-6.0 \mu \mathrm{g} / \mathrm{ml})$

\begin{tabular}{|c|c|c|c|}
\hline \multirow{2}{*}{$\begin{array}{l}\text { Piperine } \\
\text { Concentration } \\
(\mu \mathrm{g} / \mathrm{ml})\end{array}$} & \multirow[b]{2}{*}{ Peak area } & \multicolumn{2}{|c|}{ CoQ10 } \\
\hline & & $\begin{array}{c}\text { Concentration } \\
(\mu \mathrm{g} / \mathrm{ml})\end{array}$ & Peak area \\
\hline 4 & 492021 & 240 & 32221 \\
\hline 4.5 & 553185 & 270 & 37075 \\
\hline 5 & 621403 & 300 & 42095 \\
\hline 5.5 & 687251 & 330 & 47252 \\
\hline 6 & 782884 & 360 & 51768 \\
\hline
\end{tabular}

respectively. Similarly, Limit of Quantitation (LOQ) was found to be $0.69 \mu \mathrm{g} / \mathrm{ml}$ and $9.32 \mu \mathrm{g} / \mathrm{ml}$ for piperine and CoQ10 respectively. Various factors as column type, detector sensitivity and $\mathrm{pH}$ are responsible for the value of LOD and LOQ. The results are shown in Table 3.

The system precision study was accomplished by using a $100 \%$ target concentration of test sample with 6 replicates. The calculated percentage Relative Standard Deviation (\% RSD). of the area of piperine and CoQ10, six replicates should not be more than $2 \%$. The $\%$ RSD for system precision was within the limit.

The precision of a method can be explained as the degree of closeness among the individual results of the standard solution of the target concentration. Six duplicates of $100 \%$ of test concentration of piperine and CoQ10 were used for the intraday and interday precision study. The \% RSD should be less than $1 \%$ for API and $2 \%$ for the drug product. The method has accomplished the limit of \% RSD as per ICH guideline. The results are shown in Table 4.
TABLE 3: VALIDATION PARAMETERS

\begin{tabular}{lcc}
\hline Validation parameters & CoQ10 & Piperine \\
\hline Detection wavelength $(\mathrm{nm})$ & 275 & 275 \\
Linearity range $(\mu \mathrm{g} / \mathrm{ml})$ & $243-360$ & $4-6$ \\
Coefficient of & 0.997 & 0.9971 \\
determination $\left(\mathrm{r}^{2}\right)$ & $\mathrm{y}=142.84 \mathrm{x}$ & $\mathrm{y}=127365 \mathrm{x}$ \\
Regression equation & -641.86 & -7896.7 \\
Slope & 142.84 & 127365 \\
Intercept & -641.86 & -7896.7 \\
Limit of detection $(\mu \mathrm{g} / \mathrm{ml})$ & 2.79 & 0.21 \\
Limit of quantitation & 9.32 & 0.69 \\
\hline
\end{tabular}

TABLE 4: \% RSD IN METHOD PRECISION

\begin{tabular}{lcc}
\hline Precision & Piperine & CoQ10 \\
\hline Intraday $(\mathrm{n}=6)(\%$ RSD) & 0.91 & 0.97 \\
Interday ( $\mathrm{n}=6)(\%$ RSD) & 0.77 & 0.52 \\
\hline
\end{tabular}

Note: Number of injections- 6

An accuracy study was performed by adding a known amount of standard solution into the test solution, called the spiking method. $80 \%, 100 \%$ and $120 \%$ standard solution of target concentration was added to the $100 \%$ test solution. According to ICH guidelines, the percent $(\%)$ recovery should be within $98-102 \%$. The followed formula for calculating $\%$ recovery is as follows:

$\% \quad$ Recovery=Spiked concentration-Unspiked concentration/Known concentration added $\times 100$

The results are shown in Table 5.

According to USP, robustness tests the capacity of an analytical process to remain uninfluenced by minor yet deliberate changes in parameters of the method. Robustness gives some sense of an analytical method's 
TABLE 5: \% RECOVERY RESULTS OF PIPERINE AND COQ10

\begin{tabular}{lcccccc}
\hline Drug & Level (\%) & Unspiked & Spiked & Total & Amount recovered & \% Recovery \\
\hline \multirow{3}{*}{ Piperine } & 80 & 5 & 4 & 9 & 8.98 & 99.77 \\
& 100 & 5 & 5 & 10 & 10.04 & 100.40 \\
& 120 & 5 & 6 & 11 & 11.03 & 100.27 \\
CoQ10 & 80 & 300 & 240 & 540 & 534.6 & 99 \\
& 100 & 300 & 300 & 600 & 603.12 & 100.52 \\
& 120 & 300 & 360 & 660 & 657.82 & 99.67 \\
\hline
\end{tabular}

TABLE 6: \% RSD OF PIPERINE AND COQ10 IN THE STUDY OF ROBUSTNESS

\begin{tabular}{|c|c|c|c|c|c|c|c|}
\hline \multirow{2}{*}{ Drug } & \multirow{2}{*}{$\begin{array}{c}\text { Concentration } \\
(\mu \mathrm{g} / \mathrm{ml})\end{array}$} & \multicolumn{2}{|c|}{$\begin{array}{l}\text { Changed flow rate } \\
(1.00 \mathrm{ml} / \mathrm{min}) \pm 10 \%\end{array}$} & \multicolumn{2}{|c|}{$\begin{array}{c}\text { Changed composition of } \\
\text { mobile phase (ACN:THF:Water) } \\
(65: 32: 3) \pm 2 \%\end{array}$} & \multicolumn{2}{|c|}{$\begin{array}{l}\text { Changed wavelength } \\
(275 \mathrm{~nm}) \pm 2 \mathrm{~nm}\end{array}$} \\
\hline & & $\begin{array}{c}0.90 \\
\mathrm{ml} / \mathrm{min}\end{array}$ & $\begin{array}{c}1.10 \\
\mathrm{ml} / \mathrm{min}\end{array}$ & $63: 34: 3$ & $67: 30: 3$ & $273 \mathrm{~nm}$ & $277 \mathrm{~nm}$ \\
\hline Piperine (Area \% RSD) & 5 & 0.67 & 0.58 & 0.67 & 0.54 & 0.65 & 0.51 \\
\hline CoQ10 (Area \% RSD) & 300 & 0.62 & 0.79 & 0.74 & 0.94 & 0.70 & 0.66 \\
\hline
\end{tabular}

Note: Number of injections-2

TABLE 7: ASSAY DETERMINATION (\% PURITY W/W) OF THE DOSAGE FORM (QUBINOR) BY RP-HPLC

\begin{tabular}{lccc}
\hline Drug & Label claim $(\mathrm{mg} / \mathrm{ml})$ & Amount found $(\mathrm{mg})$ & \% Estimation $(\mathrm{mg} / \mathrm{tab})$ \\
\hline CoQ10 & 300 & 297.99 & 99.33 \\
Piperine & 5 & 5.01 & 100.31 \\
\hline
\end{tabular}

reliability during daily use. The results achieved were not influenced by the variation in the conditions and were in parallel with the findings for previous conditions. The results are shown in Table 6.

The assay can be defined as the test for checking the purity of the drug in a marketed formulation (Qubinor) called a percentage purity study $(\mathrm{w} / \mathrm{w})$. The estimated $\%$ purity of piperine and CoQ10 and was found to be $99.33 \%$ and $100.31 \%$ respectively. The results are shown in Table 7. Thus, procured piperine and CoQ10 were found to be in pure form.

A rapid, precise and validated RP-HPLC method was developed for the estimation of piperine and CoQ10 simultaneously from a pharmaceutical fixed dosage combination named Qubinor. This HPLC method may also offer convenience for the selective determination of piperine and CoQ10. The developed method was validated as per ICH Q2(R1) guideline. This reported method is precise, accurate, linear, sensitive and specific on the parameters of validation. This method can be applied for the quality control assay and analytical purpose in pharmaceutical industries.

\section{Acknowledgements:}

The authors are thankful to the management of ISF College of Pharmacy, Moga for providing necessary infrastructure to carry out this research work.

\section{Conflict of interests:}

The authors declared no conflict of interest.

\section{REFERENCES}

1. FLC, RLL. Isolation of a quinone from beef heart mitochondria. Biochim Biophys Acta 1957;25(1):220-1.

2. Wolf DE, Hoffman $\mathrm{CH}$, Trenner NR, Arison BH, Shunk $\mathrm{CH}$, Linn BO, et al. Coenzyme QI Structure studies on the coenzyme Q group. J Am Chem Soc 1958;80(17):4752.

3. Pravst I, Žmitek K, Žmitek J. Coenzyme Q10 contents in foods and fortification strategies. Crit Rev Food Sci Nutr 2010;50(4):269-80.

4. Muheem A, Shakeel F, Zafar S, Jahangir MA, Warsi MH, Jain $\mathrm{GK}$, et al. Development and validation of stability indicating liquid chromatographic (RP-HPLC) method for estimation of ubidecarenone in bulk drug and formulations using quality by design (QBD) approach. Braz J Pharm Sci 2018;53.

5. Tran MT, Mitchell TM, Kennedy DT, Giles JT. Role of coenzyme Q10 in chronic heart failure, angina, and hypertension. Pharmacotherapy 2001;21(7):797-806.

6. Ondarroa M, Sharma SK, Quinn PJ. Solvation properties of ubiquinone-10 in solvents of different polarity. Biosci Rep 1986;6(9):783-96.

7. Zhang Y, Åberg F, Appelkvist EL, Dallner G, Ernster L. Uptake of dietary coenzyme Q supplement is limited in rats. J Nutr 1995;125(3):446-53.

8. Fu X, Ji R, Dam J. Acute, subacute toxicity and genotoxic effect of Bio-Quinone ${ }^{\circledR}$ Q10 in mice and rats. Regul Toxicol Pharmacol 2009;53(1):1-5.

9. Miles MV, Patterson BJ, Schapiro MB, Hickey FJ, ChalfonteEvans M, Horn PS, et al. Coenzyme Q10 absorption and tolerance in children with Down syndrome: A dose-ranging trial. Pediatr Neurol 2006;35(1):30-7. 
10. Shults CW, Beal MF, Song D, Fontaine D. Pilot trial of high dosages of coenzyme Q10 in patients with Parkinson's disease. Exp Neurol 2004;188(2):491-4.

11. Abdin AA, Hamouda HE. Mechanism of the neuroprotective role of coenzyme Q10 with or without L-dopa in rotenoneinduced parkinsonism. Neuropharmacology 2008;55(8):13406.

12. Haas RH. The evidence basis for coenzyme Q therapy in oxidative phosphorylation disease. Mitochondrion 2007;7:S136-45.

13. Singh RB, Niaz MA, Kumar A, Sindberg CD, Moesgaard S, Littarru GP. Effect on absorption and oxidative stress of different oral Coenzyme Q10 dosages and intake strategy in healthy men. Biofactors 2005;25(1):219-24.

14. Badmaev V, Majeed M, Prakash L. Piperine derived from black pepper increases the plasma levels of coenzyme Q10 following oral supplementation. J Nutr Biochem 2000;11(2):109-13.

15. Govindarajan VS, Stahl WH. Pepper-chemistry, technology, and quality evaluation. Crit Rev Food Sci Nutr 1977;9(2):115225.

16. Upadhyay V, Sharma N, Joshi HM, Malik A, Mishra M, Singh BP, et al. Development and validation of rapid RP-HPLC method for estimation of piperine in Piper nigrum L. Int J Herb Med 2013;1(4):6-9.

17. Darshan S, Doreswamy R. Patented antiinflammatory plant drug development from traditional medicine. Phytother Res 2004;18(5):343-57.

18. Yang YC, Lee SG, Lee HK, Kim MK, Lee SH, Lee HS. A piperidine amide extracted from Piper longum L. fruit shows activity against Aedes aegypti mosquito larvae. J Agric Food Chem 2002;50(13):3765-7.

19. Bai YF, Xu H. Protective action of piperine against experimental gastric ulcer. Acta Pharmacol Sin 2000;21(4):357-9.

20. Meghwal M, Goswami TK. Chemical composition, nutritional, medicinal and functional properties of black pepper: A review. Sci Rep 2012;1(2):1-5.

21. Atal CK, Dubey RK, Singh J. Biochemical basis of enhanced drug bioavailability by piperine: evidence that piperine is a potent inhibitor of drug metabolism. J Pharmacol Exp Ther 1985;232(1):258-62.

22. Majeed M, Badmaev V, Rajendran R, inventors; Sabinsa Corp, assignee. Use of piperine as a bioavailability enhancer. United States patent US 5,972,382; 1999.

23. Patil UK, Singh A, Chakraborty AK. Role of piperine as a bioavailability enhancer. Int $J$ Recent Adv Pharm Res 2011;4:16-23.

24. ICH Harmonised Tripartite Guideline. Validation of Analytical Procedures: Text and Methodology Q2 (R1). International conference on harmonisation of technical requirements for registration of pharmaceuticals for human use. Geneva; 1994. p. $1-5$.

25. Shabir GA. Step-by-step analytical methods validation and protocol in the quality system compliance industry. J Valid Technol 2005;10:314-25.

26. Walfish S. Analytical methods: A statistical perspective on the ICH Q2A and Q2B guidelines for validation of analytical methods. BioPharm Int 2006;19(12):1-6. 